\title{
Access and comprehension of information by profound deaf youngsters in Brazil
}

\author{
R.C.N. Almeida ${ }^{1,2}$, R.S. Schiaffino ${ }^{1}$, V.M. Rumjanek ${ }^{1 *}$ \\ ${ }^{1}$ Instituto de Bioquímica Médica Leopoldo de Meis, Universidade Federal do Rio de Janeiro, Rio de Janeiro, Brazil. \\ ${ }^{2}$ Instituto Nacional de Educação de Surdos, Rio de Janeiro Brazil.
}

Received 30 August 2014, Accepted 23 October, 2014

\begin{abstract}
The deaf community is less well informed compared to hearing groups and this communication difficulty hampers not only the acquisition of accurate general information but also puts the deaf community at a health risk. When profound deaf students were asked about their sources of information, a younger group mentioned friends and family, and an older group answered newspapers, television, and internet as their first sources of information. However, when this second group, aged between 17-36 years old, were evaluated in relation to their capacity of reading and understanding a short piece of news it became clear in many occasions that they ignored the meaning of more than $30 \%$ of the words. This older group of students could, however, discuss certain issues that had been extensively covered by the different media. This limited access to accurate information is a problem in issues involving sexual topics. Using the school system to cover this gap, it became clear that there was a lack of knowledge related to anatomy and basic physiologic concepts, as well as sexually transmitted diseases. The questions of virginity, homosexuality, pregnancy and drug abuse were also important discussion points. The need to overcome some of these problems led to the production of DVDs and illustrated magazines with the help of the young deaf community. The deaf community deserves being better informed and different approaches should be considered to overcome this problem.
\end{abstract}

Key words: Information, young deaf community, sources of information, communication.

\section{INTRODUCTION}

The deaf community in Brazil faces a number of obstacles to access information. This results from the language barrier as they tend to use sign language as their first language and have difficulty in understanding Portuguese written language. The poor literacy skills observed among the deaf is not solely a Brazilian problem, and has been reported in a number of different countries (Furth, 1966; Miller, 2005; Wauters et al., 2006). Since 2002, Brazil has established by decree that Brazilian Sign Language (LIBRAS) should be accepted as the official language of the Brazilian deaf community. However, despite the fact that more than ten years had elapsed since the decree, it is quite clear that Brazil is still going through a transition process. Health services have

\section{*C orrespond ing a uthor. E-mail: vivian@bioqmed.ufj.br.}

Author agree that this article remain pemanently open access under the tems of the Creative Commons Attribution Lic ense 4.0 Intemational Lic ense 
Table 1. Main source of information of deaf students.

\begin{tabular}{lc}
\hline Primary school students & \\
\hline (a) Tv & $10 \%$ \\
(b) Newspaper & - \\
(c) Internet & - \\
(d) Friends/Family & $90 \%$ \\
& \\
Secondary school students & \\
(a) Tv & $35 \%$ \\
(b) Newspaper & $35 \%$ \\
(c) Internet & $20 \%$ \\
(d) Friends/Family & $10 \%$ \\
\hline
\end{tabular}

not been adjusted to attend to the deaf (Chaveiro et al., 2009; Pereira and Fortes, 2010). There is a lack of interpreters in ordinary schools and the media has not been adapted to this public. As a result, a paucity of information reaches the deaf community compared to hearing groups.

Most people, including those that work in the media, believe that the only problem faced by the deaf when accessing news will be their impossibility of listening to the radio. In addition, it is believed that this could be overcome by reading newspapers, watching TV with captions, or looking in the internet (Schiaffino and Rumjanek, 2012). A study overtaken in Brazil (Araujo, 2004) and another in Spain (Cambra et al., 2009) assessed the degree of comprehension by deaf students of television programs with captions and verified that they have difficulties in accessing the information transmitted, even if they were born within hearing families and used oral language to communicate. Our own experience is that among prelingual deaf, that communicate using sign language, the addition of small windows with a spatial description in sign language by a signer at the lower side of the television screen is also insufficient. Not only it is difficult to apprehend what is being shown at the large and small screen at the same time, but experiments with eye-tracking indicate the importance of facial expression during signing process (Emmorey et al, 2009; Muir and Richardson, 2005) added to the visual quality of the small sign language window which is quite poor.

An Austrian study on television as a source of information indicated that the deaf and hard of hearing favor both the use of captions and sign language (Kurz and Mikulasek, 2004). The inclusion of sign language as a helping resource for navigation on the Web was tested by a group in Spain (Fajardo et al., 2010). They concluded the inclusion sign language on the Web by means of a video-based navigation aid improved their access.

It is important to know the sources of information used by deaf youngsters. Not only because they are citizens entitled to be properly informed, but because it might also have important implications in their personal lives. One example is their exclusion from preventive campaigns affecting health measures. It has already been reported that the deaf population lack a proper communication with medical doctors, are less knowledgeable about health risks, and, are less informed about sexual health and sexuality issues (Peinkofer, 1994; Harmer, 1999; Tamaskar et al., 2000; Heuttel and Rothstein, 2001; Steinberg et al., 2002; Bisol et al., 2008; Alquati Bisol et al., 2008; Zazove et al., 2009; Fernandes et al., 2009; Touko et al., 2010; Pereira and Fortes, 2010; Hoang et al., 2011; Jurberg et al., 2013).

The present work attempted to verify the information sources of Brazilian deaf youths living in Rio de Janeiro, how this information is understood, the implications of incomplete and distorted information reaching this group and an experience in discussing sexuality issues and sexual transmitted diseases among the young deaf community attending a specialized school for the deaf in Brazil.

\section{METHODOLOGY}

\section{Participants}

Seventy severe-to-profound deaf students, attending a specialized school for the deaf in Rio de Janeiro, participated in our study. The participants were either in the last years of primary school or in secondary school. All of them have Brazilian Sign Language (LIBRAS) as their communication tool. Eighty percent of our sample consisted of deaf students, who became deaf before the age of three. Thirty-five percent of the participants learned LIBRAS at the age of six years or more. More than $90 \%$ had hearing parents. Only a few of them had lip-reading skills. None of the students reported in this study suffered from intellectual disabilities; their short comings resulted from their deafness.

\section{Source of information}

Twenty one deaf students were given a questionnaire containing a list of possible sources of information (Table 1). The questionnaire was anonymous and the content of the list was explained to them by a sign language interpreter. The participants belonged to two groups, a younger one with eleven students from last years of primary school and another one with ten older respondents belonging to secondary school. They were asked to mark with an $X$ their main sources of information from the list. After signing the whole content of the list, the interpreter repeated it item by item more than once and answered any questions the participants may had, to make sure it had been well understood. The whole activity was voluntary and performed in a separate room that was not their classroom.

\section{Comprehension obtained from written texts}

An older group, composed of 49 students whose age varied between 17 and 36 years, was given short pieces of news obtained from the same newspapers mentioned earlier by some of the respondents. The text was one paragraph long, containing around 15 lines, and was usually based on a health subject that had been in discussion by the general media (Dengue fever epidemic, 
Obesity, H1N1 epidemic, Cancer prevention, Air trips and thrombosis, Earthquake in Japan, President Obama announcing the death of Bin Laden, etc). This was done individually in a separate room. They were asked to take their time reading the piece of news and to underline any word that they did not understand the meaning. They were then asked to tell us in sign language (their usual form of communication) what they understood from what they had read.

\section{Discussion groups}

Discussion groups with five to six deaf students were organized. They were seated in a semicircle and asked to discuss freely about a subject, suggested by us, that had been in the spotlight, emphasized by the media. The subjects under discussion involved Olympic games, stress of modern life, dengue fever epidemics, smoking and associated health problems, a famous crime that occurred in Rio de Janeiro, street violence. The discussion groups were filmed, translated and transcribed by three different sign language interpreters.

\section{Organization of NOSS}

The Center for orientation in issues related to health and sexuality (NOSS) was organized by one of us (RCNA) in 2004 and was accepted as part of the program organization of the National Institute for Education of the Deaf (INES). The Institute has an average of 500 students per year. The aim of the center was to clarify and help deaf students that had doubts about sexual or health issues. The center was open every week day at working hours and the students were free to ask questions or talk whenever they found it necessary. The centre was composed of two hearing biology teachers and at least two deaf "educational assistants" that had been trained in health issues and capable of answering questions on the most common health problems, sexuality and sexually transmitted diseases (STD). The "educational assistants" were composed of severe-to-profound deaf professionals; two were females and one male, ages varying from 24 to 32 . All of them had finished secondary school; they were at that moment attending a distant learning course at the faculty and only one had finished her university degree. Students could clear their doubts with the "educational assistants" where privacy and confidentiality were ensured.

The center was also responsible to create material to inform the deaf community on health risks and preventive measures. To do this, "educational assistants" always participated at all stages and deaf students were asked to evaluate and criticize the material produced.

\section{RESULTS}

\section{Source of information}

The results of the questionnaires on source of information were divided into two groups, one containing the answers of younger students at the last classes of primary school and another one with older respondents belonging to secondary school. Ninety percent of the younger group answered that their main source of information was family and friends. Students from secondary school, in their majority (70\%), answered newspaper and television, followed by internet and family and friends.

\section{Comprehension obtained from written texts}

Based on the previous results suggesting that older deaf students read newspapers, and being aware of their reading difficulties, eight short pieces of news that had appeared in daily newspapers were given to 49 students and their understanding of the text was evaluated. It was found that they ignored the meaning of a number of words present in the text. For example in a text containing 90 words about H1N1 epidemic up to 18 words were underlined (20\% of the text). In another one on the Dengue epidemic up to 30 words were underlined. These were words such as: transmission, focus, insecticide, detection, hemorrhage, control, preventive measures, vaccination, contaminated, vector, immunized. Most of the underlined words were essential for the understanding of the text. In a few occasions they had access to an illustration and it was noted that in these cases they found it easier to comprehend what was the main point of the piece of news. However, there were occasions when the picture was misleading.

\section{Discussion groups}

To avoid the difficulty of the written language, seven discussion groups were organized and they were asked to discuss freely a given subject suggested by us, which had been extensively covered by the media. Even then, and considering for example a theme such as Olympic Games, the information arrived distorted.

\section{Topics raised at NOSS}

Even among hearing families the discussion of sexuality and illicit drugs is, in many instances, a difficult one. However, information may be gathered from other sources. The experience of the educational assistants at NOSS was that there was a considerable lack of knowledge among the students with a lack of basic biological concepts. The main areas of concern were pregnancy, homosexuality, virginity and STD.

\section{DISCUSSION}

In Brazil, people who are severely or profoundly deaf are less informed compared to hearing groups. As a result, the general knowledge of deaf youngsters lags behind that of a similar sample of hearing youths. Furthermore, the lack of communication leading to this difference starts very early. Hearing mothers of deaf babies tend to point less to objects naming them and tend to interact less with their deaf child. Lichtig et al. (2011) studying deaf children aged 3-6 years old, found them to be delayed in their communicative abilities, independent of their linguistic level and preferred modality of communication (Lichtig 
et al., 2011). However, different groups analyzing communicative interactions between deaf children and their parents found controversial results (discussed in VanDam et al., 2012).

In the present work, when deaf students were asked about their sources of information they could be divided into two groups: a younger (last classes of primary school) that mentioned friends and family, and a second group with older respondents (secondary school) that answered newspapers, television, and internet as their first sources of information. Similarly, when studying the problem of AIDS and sexually transmitted diseases, Heuttel and Rothstein (2011) observed that deaf students relied more on information from family and friends compared to their hearing classmates that tended to gather information from the media. In the present study, when a group of 49 deaf people, studying or working at the specialized school for the deaf, and aged between 17-36 years old, were evaluated in relation to their capacity of reading and understanding a short piece of news in daily newspapers or magazines, it was found that they had a great deal of difficulty in understanding a written text of news, and tended to pick up some keywords they understood in the text and to create a story around them. With this approach many misconceptions were made. Therefore, getting information from other deaf people immersed in the same community might perpetuate the problem.

This limited access to accurate information is even more problematic when the issue involves sexuality and the majority of the deaf comes from hearing families not fluent in sign language. Kushalnagar et al. (2011) discussed the problems resulting from the lack of parental involvement due to difficulties of parent-youth communication including sexual risk behavior. It is important to realize that deaf youngsters engage in sexual activity like other youths of this age group. If sexual and reproductive health information is not obtained at home and if they have difficulty in understanding what the media says, they rely on their friends and peers that may not be well informed as well (Joseph et al., 1995). As a result deaf youngsters are more vulnerable to sexual diseases and more exposed to sexual violence (Rusinga, 2012). A study comparing deaf and hearing adolescents in southern Brazil indicated that deaf participants scored lower on HIVIAIDS knowledge and suffered a higher rate of sexual abuse (Bisol et al., 2008).

Another possibility of informing the deaf youngsters would be through the school system. Analyzing, in 1994, how American schools for the deaf dealt with AIDS information showed that the policies regarding the subject varied from school to school and were in many instances insufficient (Deyo, 1994). In Brazil, only in 1998 the Ministry of Education created the need for Sexual Education in schools. Our own experience in Brazil involved deaf youngsters at a specialized school for the deaf (Almeida, 2013). There are around 500 students per year at the school and an average of $45 \%$ attended at some time the "chat room" of the NOSS. The majority looked for advice in questions related to pregnancy, relationships with the opposite sex, homosexuality, virginity and STD (sexually transmitted diseases). The deaf educational assistants functioned as counselors, only gave information and advice, never any kind of judgment. It was felt that it was important to have deaf counselors that shared the same culture. It became clear from our experience that there is lack of knowledge related to anatomy and basic physiologic concepts. It was also evident the lack of information related to drugs usage. This could be a reflection of their difficulty in understanding words in written Portuguese such as needle, syringe, virus, transmission; as well as difficulties of parent-youth communication.

However, a study with non-deaf young Brazilians indicated that AIDS cases are higher among females in this age group and that despite having high knowledge about STD/HIV, youths are the only age group that shows a trend toward increased HIV infection (MS, 2011). Furthermore, among girls HIV resulted from unprotected sex (MS, 2011) and adolescent alcohol and drug use were associated with unsafe sexual practices (Sanchez et al., 2013).

The need to inform deaf students in a number of issues including health risks and preventive measures led to the production of DVDs and illustrated magazines. There is no doubt that comprehension can be improved with the help of illustrations, however, the illustration must be carefully chosen or misconceptions are produced. During the H1N1 flu pandemic in 2009, a photograph in a newspaper pictured a group of people in the streets wearing masks and with features that did not look Brazilian. That particular picture was interpreted by the deaf students as meaning that the flu was a problem of a different country and did not concern them (Schiaffino and Rumjanek, 2012). Therefore, it was fundamental to receive criticisms from the young deaf community at every stage when producing material specifically aimed at this group.

But the deaf must have access to relevant information that goes beyond health issues. In the present work, when deaf secondary school students were presented with small pieces of news, covering not more than one paragraph, they had a great difficulty of understanding the context of the text and in many occasions ignored the meaning of more than $30 \%$ of the words. On the other hand, when groups of deaf students were asked to talk about certain issues that had been extensively covered by the different media, it was clear that they had some notion of the facts involved, but lacked depth.

These communication difficulties hamper not only the acquisition of accurate general information but also put the deaf community at a health risk by inhibiting preventive measures, excluding deaf patients from health 
care systems and by interfering with the relation patient/ physician (Iezzoni et al., 2004; Costa and Silva, 2012).

A better informed community might minimize such problems and attempts should be made to find different solutions and approaches to improve communication to this group.

\section{Conflict of Interests}

The authors have not declared any conflict of interests.

\section{ACKNOWLEDGEMENTS}

This work was supported by Coordenação de Aperfeiçoamento de Pessoal de Nível Superior (CAPES), Brazilian Ministry of Education, Fundação de Amparo à Pesquisa do Estado do Rio de Janeiro (FAPERJ) and FINEP.

\section{REFERENCES}

Almeida RCN (2013). [Education, management and communication in health issues for the deaf: construction, evaluation and proposals built by voices and hands] Educação, gestão e difusão em saúde para surdos: construção, avaliação e propostas construídas por vozes e mãos. Revista Espaço, Informativo Técnico Científico do Instituto Nacional de Educação de Surdos 40:52-65.

Alquati BC, Sperb TM, Moreno-Black G (2008). Focus groups with deaf and hearing youths in Brazil: improving a questionnaire on sexual behavior and HIVIAIDS. Qual. Health Res. 18(4):565-78.

Araujo VLS (2004). Closed subtitling in Brazil. In: Topics in audiovisual translation. (ed) Orero P. John Benjamins Publishing Company, Amsterdam/Philadelphia pp.199-212.

Bisol CA, Sperb TM, Brewer TH, Kato SK, Shor-Posner G (2008). HIVIAIDS knowledge and health-related attitudes and behaviors among deaf and hearing adolescents in southern Brazil. Am. Ann. Deaf 153(4):349-56.

Cambra C, Silvestre N, Leal A (2009). Comprehension of television messages by deaf students at various stages of education. Am. Ann. Deaf. 153(5):425-34.

Chaveiro N, Porto CC, Barbosa MA (2009). The relation between deaf patients and the doctor. Braz. J. Otorhinolaryngol. 75(1):147-50.

Costa LSM, Silva NCZ (2012). [Developing medical students' attitudes, knowledge and skills in healthcare for deaf people] Desenvolvendo atitudes, conhecimentos e habilidades dos estudantes de medicina na atenção em saúde de pessoas surdas. Interface - Comunicação, Saúde, Educação 16(43):1107-1117.

Deyo DA (1994). A review of AIDS policies at schools for deaf and hard of hearing students. Am. Ann. Deaf 139(2):86-95.

Emmorey K, Thompson R, Colvin R (2009). Eye gaze during comprehension of American Sign Language by native and beginning signers. J. Deaf Stud. Deaf Educ. 14(2):237-43.

Fajardo I, Parra E, Cañas JJ (2010). Do sign language videos improve Web navigation for Deaf Signer users? J. Deaf Stud. Deaf Educ. 15(3):242-62.

Fernandes JFP, Alves MDS, Barroso MGT, Oriá MOB (2009). [Awareness of sexually transmitted diseases among deaf students and educators] Conhecimento de alunos deficientes auditivos e de seus educadores relacionado às doenças sexualmente transmissíveis. Rev. Enferm. UERJ. 17(3):338-43.

Furth HG (1996). A comparison of reading test norms of deaf and hearing children. Am. Ann. Deaf, 111(2):461-2.

Harmer L (1999). Health care delivery and deaf people: practice, problems, and recommendations for change. J. Deaf Stud. Deaf Educ. 4(2):73-110.
Heuttel KL, Rothstein WG (2001). HIVIAIDS knowledge and information sources among deaf and hearing college students. Am. Ann. Deaf, 146(3):280-286

Hoang L, LaHousse SF, Nakaji MC, Sadler GR (2011). Assessing deaf cultural competency of physicians and medical students. J. Cancer Educ. 26(1):175-82.

Iezzoni LI, O'Day BL, Killeen M, Harker H (2004). Communicating about health care: observations from persons who are deaf or hard of hearing. Ann. Int. Med. 140(5):356-62.

Joseph JM, Sawyer R, Desmond S (1995). Sexual knowledge, behavior and sources of information among deaf and hard of hearing college students. Am. Ann. Deaf, 140(4):338-45.

Jurberg C, Verjovsky M, Machado G, Maia T, Rumjanek VM (2013). Overcoming barriers: the development of an animated film on HPV for deaf and hearing students. Scholarly J. Sci. Res. Essay 2(2):2733.

Kurz I, Mikulasek B (2004). Television as a source of information for the deaf and hearing impaired. Captions and Sign Language on Austrian TV. Meta: Journal des Traducteurs/Meta: Translators' J. 49(1):81-88.

Kushalnagar P, Topolski TD, Schick B, Edwards TC, Skalicky AM, Patrick DL (2011). Mode of communication, perceived level of understanding, and perceived quality of life in youth who are deaf or hard of hearing. J. Deaf Stud. Deaf Educ. 16(4):512-23.

Lichtig I, Couto MI, Mecca FF, Hartley S, Wirz S, Woll B (2011). Assessing deaf and hearing children's communication in Brazil. J. Commun. Disord. 44(2):223-35.

Miller P (2005). Reading comprehension and its relation to the quality of functional hearing: evidence from readers with different functional hearing abilities. Am. Ann. Deaf 150(3):305-23.

MS BMoH. Boletim Epidemiológico do AIDS/DST [Epidemiological Bulletin on AIDS/STD] (2011). (ed.) Brasilia: Ministério da Saúde; p.159.

http://www.aids.gov.br/sites/default/files/anexos/publicacao/2011/506 52/boletim_aids_2011_final_m_pdf_26659.pdf

Muir LJ, Richardson IE (2005). Perception of sign language and its application to visual communications for deaf people. J. Deaf Stud. Deaf Educ. 10(4):390-401.

Peinkofer JR (1994). HIV education for the deaf, a vulnerable minority. Public Health Rep. 109(3):390-396.

Pereira PC, Fortes PA (2010). Communication and information barriers to health assistance for deaf patients. Am. Ann. Deaf 155(1):31-7.

Rusinga O (2012). Perceptions of deaf youth about their vulnerability to sexual and reproductive health problems in Masvingo District, Zimbabwe. Afr. J. Reprod. Health 16(2):271-82.

Sanchez ZM, Nappo SA, Cruz JI, Carlini EA, Carlini CM, Martins SS (2013). Sexual behavior among high school students in Brazil: alcohol consumption and legal and illegal drug use associated with unprotected sex. Clinics (Sao Paulo) 68(4):489-494.

Schiaffino RS, Rumjanek VM. (2012). [Does Science Communication Hear the Deaf? How access to informal knowledge interferes with the formation of scientific knowledge of the deaf population] A Divulgação Científica é Surda aos Surdos? Como o acesso ao conhecimento informal interfere na formação do conhecimento científico da população surda. Rev. Tempo Brasileiro 188:79-96.

Steinberg AG, Wiggins EA, Barmada CH, Sullivan VJ (2002). Deaf women: experiences and perceptions of healthcare system access. J. Women's Health (Larchmt) 11(8):729-41.

Tamaskar P, Malia T, Stern C, Gorenflo D, Meador H, Zazove P (2000). Preventive attitudes and beliefs of deaf and hard-of-hearing individuals. Arch. Fam. Med. 9(6):518-25.

Touko A, Mboua CP, Tohmuntain PM, Perrot AB (2010). Sexual vulnerability and HIV seroprevalence among the deaf and hearing impaired in Cameroon. J. Int. AIDS Soc. 13:5.

VanDam M, Ambrose SE, Moeller MP (2012). Quantity of parental language in the home environments of hard-of-hearing 2-year-olds. J. Deaf Stud. Deaf Educ. 17(4):402-20.

Wauters LN, Van Bon WHJ, Telling AEJM (2006). The reading comprehension of Dutch deaf children. Read. Writ. 19(1): 49-76.

Zazove P, Meador HE, Reed BD, Sen A, Gorenflo DW (2009). Cancer prevention knowledge of people with profound hearing loss. J. Gen. Int. Med. 24(3):320-326. 